\title{
MEDIACIÓN FAMILIAR Y CIVIL EN ESPAÑA: UNA INSTITUCIÓN (iRECIENTE?) QUE HA LLEGADO PARA QUEDARSE
}

\author{
Autora: Elena Laurobal \\ Profesora Titular Derecho Civil \\ Universidad de Barcelona
}

\section{Resumen}

Este artículo examina la mediación como mecanismo de resolución alternativa de conflictos a partir de su regulación "multi-level", en concreto, la Directiva 2008/52/ CE, la Ley 5/2012 y las diferentes leyes autonómicas. Permiten formular un concepto de mediación e identificar sus principios rectores (voluntariedad, confidencialidad, imparcialidad y neutralidad). Se da la paradoja de que, pese a las ventajas del procedimiento de mediación (es breve, económico, y satisfactorio para las partes), se utiliza muy poco. Por ello se propugnan diversas medidas, entre las que destaca la formación de los abogados como asesores de las partes (no como mediadores).

${ }^{1}$ e.lauroba@ub.edu; el presente trabajo se inscribe en el proyecto DER 2014-54267-P; también quiero mencionar el Proyecto "Análisis jurídico económico de la mediación como metodología de la resolución de conflictos en el ámbito asegurado" que desarrollan diversos profesores de la Universidad de Barcelona con la empresa DAS, y enriquece las investigaciones. 
Palabras clave: mediación civil; mediación familiar; legislación multi-level; procedimiento estructurado; voluntariedad; mediación obligatoria; confidencialidad; imparcialidad; neutralidad; coordinador parental; menores; medidas de fomento de la mediación.

\title{
Family and Private Mediation in Spain: A (new?) Institution that has come to stay
}

\begin{abstract}
This paper examines Mediation as an Alternative Dispute Resolution process [ADR] in light of its "multi-level" legal scheme, namely the Directive 2008/52/ EC, the Act 5/2012 and the autonomic laws. These Acts provide a concept of mediation and identify its main principles (i. e. voluntariness, confidentiality, impartiality and neutrality). There is, however, an interesting paradox: despite the well-known advantages of mediation (it entails an economical procedure and affords adequate satisfaction to the parties), it remains underused in the European jurisdictions. This paper calls, therefore, for measures to encourage its use, such as an adequate training for lawyers as to the appropriate manner in which to provide advice during the procedure.
\end{abstract}

Key words: private meditation; family mediation; multi-level legislation; structured process; voluntary basis; mandatory mediation; confidentiality; impartiality; neutrality; parental coordinator; minors; measures to improve mediation.

\section{PRESENTACIÓN}

Decía Martín Diz en un artículo publicado en el 2014 que "Más que como una novedad, aludir a la mediación en Derecho privado en España implica referirse ya a una realidad, a una opción legalmente considerada y, parece, totalmente desa-

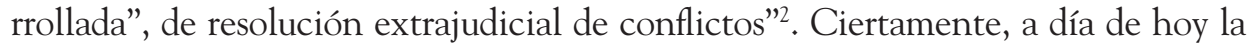
mediación no resulta ajena a ningún operador jurídico y las discusiones sobre su mejor implantación ocupan artículos y encuentros. Ahora ya no se trata de diluci-

\footnotetext{
${ }^{2}$ Martín Diz, F., "Mediación en derecho privado: nuevas perspectivas prácticas", Revista General del derecho procesal, (núm. 33, 2014), p. 2.
} 
dar si es una figura útil para la resolución de conflictos y la tuición de los ciudadanos (justiciables), sino que, dándolo por hecho, se persigue arbitrar los mejores mecanismos para su empleo efectivo. Hemos pasado de deplorar su desconocimiento a preguntarnos cómo es posible que, constatados sus beneficios de manera unánime, la mediación no haya arraigado fuertemente en la práctica. Eso pese a la consolidación de la profesión de mediador y al reciente soporte legislativo en nuestro país, que se corresponde con una apuesta de la Unión Europea desde hace ya veinte años y a la decidida implicación, en determinados sectores, de las administraciones públicas -significativamente las autonómicas-. Pero puede objetarse que, pese a todo, ese entusiasmo desbordante no se traduce en el empleo habitual/cotidiano de la mediación: una situación que se ha calificado de paradójica. Los esfuerzos siguen asociados a experiencias voluntariosas y a la multiplicación de cursos de formación en mediación, de calidad variable. No podemos hablar de una generalización racional y exitosa. Y todavía se desconocen muchos aspectos vinculados a la mediación.

También, a día de hoy, se ha superado cualquier controversia respecto del encaje de la mediación y del principio de tutela judicial efectiva. Si en algún momento se debatió si el recurso a otras vías podía conculcar un derecho fundamental de la ciudanía, hoy resulta incontrovertido que el mejor desarrollo de dicho derecho conlleva dar la posibilidad a los ciudadanos de optar por las herramientas más adecuadas para la gestión de su conflicto ${ }^{3}$. Hoy coincidimos en que existen otros modos de realizar la tutela jurídica diferentes de la tutela jurisdiccional, modos que quedan englobados en la noción general de "sistema de justicia". Precisamente la disponibilidad del objeto del proceso que caracteriza la mayoría de los procesos civiles, hace que este sea un campo especialmente satisfactorio para recurrir a la mediación.

Con el empleo de los Alternative Dispute Resolution (en adelante ADR) en ningún caso se impide el acceso a los tribunales. Lo que se persigue es que los tribunales constituyan el último recurso para la gestión del conflicto. Lo constata la Exposición de Motivos de la Ley 5/2012, de 6 de julio, de mediación en asuntos civiles y mercantiles, cuando establece: "Como institución ordenada a la paz jurídica, [la mediación] contribuye a concebir a los tribunales de justicia en este sector del ordenamiento jurídico como un último remedio, en caso de que

\footnotetext{
${ }^{3}$ Morales Fernández, M ${ }^{a}$ G., "La mediación, contenido de la tutela efectiva”, en Lauroba, E.-Ortuño, P., Mediación es Justicia. El impacto de la Ley 5/2012, de Mediación civil y mercantil, Ed. Huygens, Barcelona, 2014, p. 99: “... El derecho fundamental reconocido en la constitución es el mínimo: desde ahí, crece y se expande en el ejercicio que cada individuo hace de él. Desde luego, y lo que al derecho a la tutela judicial efectiva se refiere, este mínimo consiste en que el Estado establezca un Sistema Universal de Administración de Justicia Universal, a través del cual se garantice que cualquier sistema que se produce en la sociedad pueda acabar residenciado ante un órgano judicial que tendrá que dar una respuesta al mismo fundada en Derecho, incluida la inadmisión". Vid. asimismo Alastruey, R., "Argumentario sobre la búsqueda de soluciones negociadas en el proceso civil" [http://www.mediacion.icav.es/archivos/contenido/1055.pdf, última consulta 11.4.2016] que (p.3 y ss.) analiza "La necesidad de hallar la mejor solución posible como manifestación de la tutela efectiva: el mandato constitucional (art. 117 vs. art. 24)"
} 


\section{Elena Lauroba}

no sea posible componer la situación por la mera voluntad de las partes"4. Por su adaptabilidad al conflicto concreto, el acrónimo ADR también se ha releído, de manera inteligente, como Appropiate Dispute Resolution, pero todavía nos gusta más conceptuarlos como PDR: Primary Dispute Resolution.

Dicho esto, el presente trabajo pretende situar, todavía, el concepto de la mediación y repasar el andamiaje normativo que la fundamenta en España, esto es, la Directiva 2008/52/CE del Parlamento Europeo y del Consejo, de 21 de mayo de 2008, sobre ciertos aspectos de la mediación en asuntos civiles y mercantiles (en adelante DCAM), la Ley 5/2012, de 6 de julio, de mediación en asuntos civiles y mercantiles (en adelante LMACM) y las numerosas leyes autonómicas. Prestaremos especial atención a la Ley catalana 15/2009, de 22 de julio, de mediación en el ámbito del derecho privado (en adelante LMADP), atendiendo a su carácter pionero (pasa del ámbito familiar al ámbito del derecho privado) y a la procedencia de quien escribe. En terminología cada vez más arraigada, ese despliegue normativo multi-level. Concluiremos con algunas reflexiones, desde la voluntad de contribuir al fomento de la mediación.

\section{LA PRESENTACIÓN DE LA INSTITUCIÓN "MEDIACIÓN"}

\subsection{La fijación del concepto}

Señala Ortuño -referencia determinante para comprender el funcionamiento de la mediación en nuestro país- que la mediación es "una metodología de intervención en la gestión o en el manejo de conflictos" ${ }^{5}$. Ciertamente, su empleo para una tipología muy diversa de controversias dificulta una definición acotada ${ }^{6}$, pero aun así, vamos a intentar presentar un concepto de la institución, con el soporte de las leyes mencionadas supra.

\footnotetext{
${ }^{4}$ Podemos, no obstante, apuntar que esa pertinente afirmación queda deslucida acto seguido cuando señala "y puede ser un hábil coadyuvante para la reducción de la carga de trabajo de aquéllos, reduciendo su intervención a aquellos casos en que las partes enfrentadas no hayan sido capaces de poner fin, desde el acuerdo, a la situación de controversia”. La obsesión por la reducción de costes, adecuada, necesaria desde una buena gestión de lo público, no debe ser sin embargo el estribillo recurrente de todo análisis de la mediación.

${ }^{5}$ Ortuño, P., "Comentario al artículo 1. Concepto”, en Castillejo Manzanares, R. (dir.) Alonso Salgado, C y Rodríguez Álvarez, A. (coord.), Comentarios a la Ley 5/2012, de mediación en asuntos civiles y mercantiles, Tirant lo Blanch, Valencia, 2013, p.21. Vid. asimismo Marques Cebola, C., La mediación, Editorial Marcial Pons, Madrid, Barcelona, 2013.

${ }^{6}$ Ortuño, "Comentario...", cit., pp. 21-22: "no se trata de definir una institución propia del ámbito del derecho, ni tampoco un determinado tipo de procedimiento legal, que es lo que a veces se interpreta de manera errónea al englobar la mediación en la categoría de procedimiento legal extrajudicial, de forma conjunta con el arbitraje o la conciliación. La mediación es una actividad mucho más compleja”.
} 
El art. 3 DMCM define la mediación como?

a) (...) Un procedimiento estructurado, sea cual sea su nombre o denominación, en el que dos o más partes en un litigio intentan voluntariamente alcanzar por sí mismas un acuerdo sobre la resolución de su litigio con la ayuda de un mediador. Este procedimiento puede ser iniciado por las partes, sugerido u ordenado por un órgano jurisdiccional o prescrito por el Derecho de un Estado miembro $(. . .)^{8}$

La LMACM recoge (reproduce) sus coordenadas básicas, sin otros aspectos relevantes:

"Se entiende por mediación aquel medio de solución de controversias, cualquiera que sea su denominación, en que dos o más partes intentan voluntariamente alcanzar por sí mismas un acuerdo con la intervención de un mediador".

Y, por último, el art. 1 LMADP [Concepto y finalidad de la mediación] persigue una denominación que podríamos calificar "de máximos" y por tanto útil para situar el concepto:

"A los efectos de la presente ley, se entiende por mediación el procedimiento no jurisdiccional de carácter voluntario y confidencial que se dirige a facilitar la comunicación entre las personas, para que gestionen por ellas mismas una solución a los conflictos que las afectan, con la asistencia de una persona mediadora que actúa de modo imparcial y neutral.

2. La mediación, como método de gestión de conflictos, pretende evitar la apertura de procesos judiciales de carácter contencioso, poner fin a los ya iniciados o reducir su alcance."

Las definiciones nos permiten destacar varios índices. En concreto: "procedimiento estructurado", voluntariedad de la acción de las partes y "ayuda” del mediador.

${ }^{7}$ En todo caso, conviene tener en cuenta la definición en el Código de Conducta Europeo para mediadores http://ec.europa.eu/civiljustice/adr/adr_ec_code_conduct_es.pdf: "[s]e entenderá por mediación cualquier procedimiento, con independencia de cómo se denomine o a él se refiera, en el que dos o más partes en un conflicto de intereses acuerden voluntariamente intentar resolverlo con la asistencia de un tercero, denominado en lo sucesivo, "el mediador"”.

${ }^{8}$ Es una definición más desarrollada que la de la Propuesta de Directiva de 22 de octubre 2004: “"“Mediación": todo proceso, sea cual sea su nombre o denominación, en que dos o más partes en un litigio son asistidas por un tercero para alcanzar un acuerdo sobre la resolución del litigio, independientemente de si el proceso es iniciado por las partes, sugerido u ordenado por un órgano jurisdiccional, o prescrito por el Derecho nacional de un Estado miembro". 
La DCAM califica la mediación de "procedimiento estructurado", una precisión que el legislador nacional orilló. Dicho calificativo había sido objeto de un largo debate durante las negociaciones y reuniones previas al texto comunitario final. Con él "se quiso significar que la mediación no es la intervención de cualquier tercero en el proceso de solución de un conflicto (...) sino que dicha intervención ha de obedecer a una estructura preconcebida de carácter típico y singular por lo que únicamente puede ser llamada técnicamente mediación la intervención de un tercero en base a un mínimo grado de formalidad, siempre que dicha intervención obedezca a unos principios y utilice una metodología adecuada" . Eso no obsta, añadimos, para que estemos ante una estructuración modulable por las partes. Así lo explica el Considerando 13: "La mediación a que se refiere la presente Directiva debe ser un procedimiento voluntario, en el sentido de que las partes se responsabilizan de él y pueden organizarlo como lo deseen y darlo por terminado en cualquier momento". Por ello, cabe que el mediador convenga con las partes y sus abogados aspectos relativos al procedimiento (significativamente la duración o los mecanismos de rotación $)^{10}$. Es quizás la conciencia de la controversia la que llevó al legislador estatal a no incorporar dicho calificativo en la LMACM. Curiosamente, en el Anteproyecto de Ley de Mediación del 2010 sí se había recogido, aunque la condición de estructurada se predicaba de la mediación como "negociación"11. La conceptuación como "negociación" fue contestada por inexacta en el Informe del Consejo General del Poder Judicial al proyecto, y se eliminó ${ }^{12}$.

\footnotetext{
${ }^{9}$ Ortuño, P., "Apuntes críticos sobre la Ley 5/2012, de mediación civil y mercantil”, Anuario de Mediación y solución de conflictos, (núm. 1, 2013), p.56, y concluye: "La precisión no es baladí, puesto que de la misma va a depender la exigencia de la cualificación y preparación técnica del mediador".

${ }^{10}$ Como apunta Gutiérrez Sanz, M $M^{a}$. R., "El procedimiento de mediación: transposición de la Directiva 2008/52/CE por la Ley 5/2012 de 6 de julio, de mediación en los asuntos civiles y mercantiles", en Hualde, T. (dir.) y Mestrot, M. (coord.), La mediación en asuntos civiles y mercantiles. La transposición de la Directiva 2008/52 en Francia y en España, La Ley, Madrid, 2013, p. 224: "para que la mediación sea eficaz tiene que darse la posibilidad de que las técnicas, herramientas e instrumentos, incluso los plazos que se acuerden, sean los adecuados a cada conflicto y a cada individuo. No puede, por tanto, existir una única estructura con elementos rígidos e inalterables, porque no existe una única solución para todos los conflictos, aunque sean de similar naturaleza".

11 "Artículo 1. Concepto. A los efectos de esta Ley se entiende por mediación aquella negociación estructurada de acuerdo con los principios de esta ley, en que dos o más partes en conflicto intentan voluntariamente alcanzar por sí mismas un acuerdo para su resolución con la intervención de un mediador".

12 "El término 'negociación' no es afortunado, por cuanto se suele emplear para referirse a un medio alternativo de resolución de disputas aún más informal que la propia mediación, caracterizado por la no intervención de un tercero. La negociación suele ser una fase previa en el intento de gestionar una controversia que precede tanto a la mediación, como al arbitraje y la decisión jurisdiccional. Así pues, en lugar de asimilar la mediación a otro concepto más o menos análogo que constituya igualmente una especie dentro del género 'medios alternativos de solución de conflictos', cabe recomendar el empleo directo de esta expresión u otra similar ('método alternativo para la resolución de controversias' o 'para la superación voluntaria de disputas') en la definición inicial de la mediación...” [http://www.poderjudicial.
} 
Como último material, vale la pena releer el art. 1 LMADP, en el que destacan, creemos, dos aspectos. Por un lado, esa voluntad de procurar una definición de máximos con atención específica a los principios nucleares, agrupados en dos ámbitos. La voluntariedad y confidencialidad, como principios identificadores del proceso y la imparcialidad/neutralidad, como principios propios de la tarea del mediador. Sobre ellos volveremos en el apartado siguiente.

Por otro lado -y nos parece especialmente relevante-, el segundo párrafo del art. 1 LMADP define la mediación como "método de gestión de conflictos". Más allá de manifestar que el término "método" evoca esa "metodología" ya apuntada (por tanto un territorio vasto), queremos destacar que se habla de "gestión", en la convicción de que la mediación es útil incluso cuando no se obtienen soluciones o acuerdos ${ }^{13}$. En 2008, el Protocolo para la implantación de la mediación familiar intrajudicial en los Juzgados y Tribunales que conocen de procesos de familia, que facilitó el CGPJ, apuntaba que con la mediación se pretendía que "se dé la oportunidad a las partes de llegar a una solución consensuada por ellos con la ayuda de un tercero, o al menos se reduzcan las materias en discordia o sirva para pacificar el conflicto entre ellos. En el juzgado a veces es suficiente con que el enconamiento disminuya y la comunicación entre la pareja mejore"14. A nuestro juicio, desplazar el eje de solucionar a gestionar es relevante: implica atender a otros beneficios de la mediación más allá de los costes menores o el ahorro de tiempo a la vez que incorpora una connotación transformativa no desdeñable.

\subsection{Un apunte respecto de los principios que presiden la mediación}

Hemos visto como las definiciones de mediación incorporan repetidamente los principios que conforman la figura. Además, las leyes autonómicas dedican sistemáticamente un capítulo a la enumeración y desarrollo de dichos principios. Baste recordar, por ejemplo, el artículo 10 LMF País Vasco, que identifica diez principios y establece su contenido: (a) voluntariedad; (b) confidencialidad; (c) transparencia; (d) respeto al Derecho; (e) imparcialidad; (f) neutralidad; (g) flexibilidad; (h) debate contradictorio; (i) inmediatez; ( $\mathrm{j}$ ) buena fe, colaboración y mantenimiento del respeto entre las partes. Es, probablemente, una opción legislativa con un plus pedagógico, en que coexisten los principios "nucleares" con otros índices relevantes, pero no consustanciales a las presentaciones al uso de la mediación.

es/cgpj/es/Poder-Judicial/Consejo-General-del-Poder-Judicial/Actividad-del-CGPJ/Informes/Informeal-Anteproyecto-de-Ley-de-mediacion-en-asuntos-civiles-y-mercantiles].

${ }^{13}$ Vall, A., "Sistemas mixtos de gestión colaborativa de conflictos", en Lauroba, M ${ }^{\mathrm{a}}$ E.- Barral, I. y Viola, I., Materiales jurídicos del Libro Blanco de la mediación en Cataluña, Generalitat de Catalunya, Barcelona, 2011, pp. 263 y ss.

${ }^{14}$ P. 5.http://www.lexfamily.es/revista.php?codigo=396 El Protocolo fue elaborado por los magistrados M Teresa Martín Najera, Margarita Pérez Salazar y José Luis Utrera Gutiérrez, y traía causa del Programa Piloto que se realizó en 6 juzgados en el 2006. 


\section{Elena Lauroba}

Aquí queremos mencionar los cuatro principios emblemáticos, que se incorporan al concepto de la institución: la voluntariedad, la confidencialidad, la imparcialidad y la neutralidad.

\subsubsection{La Voluntariedad}

La voluntariedad es un principio nuclear de la mediación y se ha llegado a considerar, además, un presupuesto de su funcionamiento ${ }^{15}$. Tiene una doble vertiente: como libertad para acogerse al procedimiento y como libertad para desistir en cualquier momento. La primera vertiente -en ningún caso la segunda-, admite una serie de modulaciones que no contestan el principio. Básicamente, la posible obligatoriedad de tener que acudir a la mediación en algunos casos, como ha establecido la ley italiana al transponer la Directiva, en una opción que hace correr ríos de tinta, al ser considerada una vía inapelable de promoción de la mediación ${ }^{16}$. También aquí se deben mencionar las cláusulas de sujeción a la mediación, que a día de hoy proliferan en las webs de cámaras de comercio y colegios profesionales. Como efecto inmediato posibilitan el ejercicio de la declinatoria, ex art. 39 LEC, aunque podemos ir más allá: siguiendo la construcción de Ginebra y Tarabal, cabe distinguir entre eficacia ordinaria de la cláusula (referida al cumplimiento) y eficacia extraordinaria (ligada al incumplimiento $)^{17}$.

\subsubsection{La confidencialidad}

La confidencialidad es el otro aspecto clave para el éxito de la mediación. En la sucinta relación de aspectos que preocupaban al legislador comunitario, aparece como uno de los ejes a contemplar (art.7 DCAM)). Identificable de manera intuitiva, se predica no sólo en relación al mediador, sino a las partes. El art. 9 LMACM lo recoge de manera completa:

${ }^{15}$ Lauroba, E., Barral, I., Tarabal, J. y Viola, I., "La construcción institucional y jurídica de la mediación”, Libro Blanco de la mediación en Cataluña, www.llibreblancmediacio.com. Asimismo, Lo recuerda el Preámbulo ley 5/2012: "El modelo de mediación se basa en la voluntariedad y libre decisión de las partes y en la intervención de un mediador".

${ }^{16}$ Impagnatiello, G., "La mediazione civile in Italia", en Iglesias Canle, I. C., Mediación, justicia y Unión Europea, Tirant lo Blanch, Valencia, 2014, pp.174-177 y Cavuoto, E., "La nueva mediación obligatoria en Italia", ídem, pp. 299-310.

${ }^{17}$ Ginebra, E. y Tarabal, J., "La obligatoriedad de la mediación: derivada de la voluntad de las partes: las cláusulas de mediación”, Indret, (núm. 4, 2013), http://www.raco.cat/index.php/InDret/article/ viewFile/270125/357682, p. 20 ss; ID, "Mediación obligatoria e inducción a la mediación”, en Lauroba, E. y Ortuño, P., Mediación es Justicia. El impacto de la Ley 5/2012, de Mediación civil y mercantil, Huygens, Barcelona, 2014, pp. 227-234. 
"1. El procedimiento de mediación y la documentación utilizada en el mismo es confidencial. La obligación de confidencialidad se extiende al mediador, que quedará protegido por el secreto profesional, a las instituciones de mediación y a las partes intervinientes de modo que no podrán revelar la información que hubieran podido obtener derivada del procedimiento".

Acto seguido recuerda que los mediadores no pueden declarar ni aportar documentación en un procedimiento judicial o un arbitraje derivada de la mediación anterior salvo que las partes les dispensen (de manera expresa y por escrito) de dicho deber, o bien cuando los jueces de la jurisdicción penal soliciten dicha información mediante resolución motivada ${ }^{18}$.

La observancia de ese principio estimula de manera inequívoca la cooperación de las partes y por ello las leyes lo traen a colación en diferentes preceptos. Por ejemplo, en la regulación del procedimiento en la LMACM: arts. 17, 18, 21.3, 22. Vale la pena detenernos un momento en el art.17, con la rúbrica "Información y sesiones informativas". Precisa que “... la información de qué parte o partes no asistieron a la sesión no será confidencial”. Esta precisión demuestra que la sesión informativa no integra propiamente el procedimiento de mediación, y que el juez dispondrá de una información valiosa para dilucidar las actitudes cooperativas... ${ }^{19}$. Más allá de precisiones técnicas -como la interesante distinción entre confidencialidad en sentido positivo y negativo ${ }^{20}-$, la confidencialidad debe leerse en términos de confianza, que es el elemento clave para conseguir el éxito del proceso ${ }^{21}$.

\footnotetext{
${ }^{18}$ En definitiva, cuando es necesario tutelar un interés superior. Como apuntan Merino Ortiz, C. y Lasheras Herrero, P., "Comentario al artículo 9", en Castillejo Manzanares, R. (dir.) y Alonso Salgado, C. y Rodríguez Alvarez, A. (coords.), Comentario a la Ley 5/2012, de Mediación en asuntos civiles y mercantiles, Tirant lo Blanch, Valencia, 2013, p. 114, "Tal es el caso del interés de un menor, el peligro contra la integridad física o psíquica de uno de los miembros de la pareja o de un tercero y la aparición de indicios de la existencia de un delito".

${ }^{19}$ Lo que -se ha hecho notar- puede ser una circunstancia cuestionable, dado que "puede comprometer la imparcialidad del juzgador, inclinando la balanza a favor de aquella [parte] que ha decidido acudir a la mediación"(Merino Ortiz, C. y Lasheras Herrero, P., cit.supra, p. 118.

${ }^{20}$ Viola, I., "La confidencialidad en el procedimiento de mediación”, en Lauroba, Mª E., Barral, I, y Viola, I, Materiales jurídicos del Libro Blanco de la mediación en Cataluña, Generalitat de Catalunya, Barcelona, 2011, p. 168.

${ }^{21}$ Viola, "La confidencialidad...", cit., pp.165-167. Bernal Samper, T., "La confidencialidad como principio rector e identificador de la mediación III", en Lauroba, E. y Ortuño, P., Mediación es Justicia. El impacto de la Ley 5/2012, de Mediación civil y mercantil, Huygens, Barcelona, 2014, centra su texto justamente en la confianza, y recalca que la confianza en el mediador depende de dos hechos importantes: la consistencia y la competencia (pp. 201-211). Vid. también las contribuciones de Vidal Teixidó, Pereda Gámez y Méndez Pichot y Casellas Estévez, en el mismo libro.
} 


\subsubsection{La imparcialidad y la neutralidad}

Pese a tratarse de dos principios independientes, a menudo se mezclan o confunden -y por ello hemos decidido abordarlos conjuntamente-. Ya los diferenciaba la Recomendación R (98) 1 del Consejo de Ministros en los Estados miembros sobre la mediación familiar, de 21 de enero de 1998: el mediador es imparcial en sus relaciones con las partes y neutral con respecto al resultado del proceso de mediación.

La imparcialidad es un rasgo común a la mayoría de mecanismos de resolución de conflictos en que un tercero interviene. Implica que el mediador no tiene que apoyar el interés o los puntos de vista de ninguna de las partes en conflicto, ni actuar en perjuicio de sus posiciones. Para garantizar la imparcialidad, se regula el conflicto de intereses.

La neutralidad se predica en relación a las facultades del mediador respecto del resultado del proceso de mediación. Dado que le corresponde asistir y facilitar, carece de poder decisorio. Dicho esto, a día de hoy la cuestión es dilucidar el alcance de su asistencia. Tradicionalmente la mediación se ha concebido -y es quizás consustancial al conflicto familiar- como una mediación facilitativa, pero en algunos ámbitos -así lo constata la práctica- el mediador llega a sugerir posibles vías o -llamemos a las cosas por su nombre- soluciones. Singularmente, el art. 7.2. Ley gallega, 4/2001, de 31 de mayo, reguladora de la mediación familiar, prescribe: "La actividad mediadora tendrá por objeto la prestación de una función de auxilio o apoyo a la negociación entre las partes, concretándose, en su caso, en la facultad de la persona mediadora de proponer soluciones, a aceptar o no libremente por los sujetos en conflicto...". Esa facultad resulta ajena a las coordenadas de las restantes leyes autonómicas, aunque el art. 8 [Principios informadores] incorpora "los postulados de imparcialidad y neutralidad de la persona mediadora"22. Visto a posteriori, la fórmula no difiere en exceso de la definición que da la ley italiana vigente, al transponer la Directiva, de la mediación ${ }^{23}$. Probablemente el uso progresivo de la mediación para una heterogeneidad de conflictos privados conlleve una serie de matices en la configuración/ inteligencia del alcance de la intervención del mediador. En ese sentido, el art. 6.2 LMADP señala que el mediador "no puede imponer ninguna solución ni una medida concreta". Si lo releemos, el verbo utilizado es "imponer". ¿Cabe conjeturar que podría sugerirlas?

22 "Artículo 8. 2. El procedimiento de mediación habrá de desarrollarse conforme a los postulados de imparcialidad y neutralidad de la persona mediadora, debiendo quedar garantizado que ésta respetará los puntos de vista de las partes y preservará su igualdad en la negociación, absteniéndose asimismo de promover actuaciones que comprometan su necesaria neutralidad".

23 “a) Mediazione: l'attività, comunque denominata, svolta da un terzo imparziale e finalizzata ad assistere due o più soggetti nella ricerca di un accordo amichevole per la composizione di una controversia, anche con formulazione di una proposta per la risoluzione della stessa". 


\section{EL MARCO NORMATIVO "MULTI-LEVEL"}

\subsection{Una voluntad europea ininterrumpida}

\subsubsection{Las iniciativas previas a la Directiva 2008/52/UE}

El primer pronunciamiento de referencia es la Recomendación n. ${ }^{\circ}$ 7/1981 del Comité de Ministros a los Estados miembros, relativa a medidas tendentes a facilitar el derecho de acceso a la justicia. Adviértase que es -como los siguientes-del Consejo de Europa. La Recomendación perseguía la adopción, por parte de los Estados, de medidas conducentes a la mejor implementación del derecho de acceso a la justicia recogido en el art. $6 \mathrm{CEDH}$, en general mediante la adopción de vías para la solución amigable de los conflictos, individualizando la conciliación.

En la misma línea, 5 años después, la Recomendación $n^{\circ}$ 12/1986, del Comité de Ministros a los Estados miembros, relativa a medidas tendentes a prevenir y reducir la sobrecarga de trabajo de los Tribunales de Justicia, abogaba por el empleo de los ADR e identificaba de manera expresa la conciliación, el arbitraje y la mediación. El esfuerzo del Comité se visibiliza, una década después, en otra Recomendación, que a menudo se considera el impulso inmediato para numerosas iniciativas estatales europeas de mediación familiar: la Recomendación $n^{0}$ 1/1998, del Comité de Ministros a los Estados miembros, sobre mediación familiar del Consejo de Europa ${ }^{24}$. Esta Recomendación destacaba la eficacia de la mediación -con el soporte de las experiencias analizadas en los diferentes países-, dado que reducía los conflictos de las partes, posibilitaba los convenios amistosos, aseguraba el mantenimiento de las relaciones paternofiliales y en definitiva mejoraba la comunicación en el seno de las familias. Lo más interesante, a nuestro juicio, es que identificaba y explicitaba los principios básicos para regular la mediación (organización, acceso, desarrollo del proceso... $)^{25}$.

Un año después, el Consejo aprobaba la Recomendación $n^{\circ} / 1999$, del Comité de Ministros a los Estados miembros sobre mediación en cuestiones penales y en el 2001 adoptaba un pronunciamiento muy interesante, por necesitado de mayores reflexiones: la Recomendación $n^{\circ}$ 9/2001 del Comité de Ministros a los Estaos miembros sobre alternativas a los litigios entre autoridades administrativas y particu-

${ }^{24}$ Así lo recuerda Macho Gómez, C., "Origen y evolución de la mediación: el nacimiento del «movimiento ADR» en Estados Unidos y su expansión a Europa”, Anuario de Derecho Civil, (vol. 67, núm. 3, 2014), p. 974, que menciona las iniciativas de Alemania, el mismo 1998; Austria, con las reformas de 1999 y 2001; Francia -a partir del informe Sassier, de 2001, que dio lugar a la Ley del 2002-y la propia España, con la multiplicación de los esfuerzos autonómicos. Una espléndida introducción a los esfuerzos de la UE, en Esplugues Mota, C., "El régimen jurídico de la mediación civil y mercantil en conflictos transfronterizos en España tras la ley 5/2012, de 6 de julio", Boletín mexicano de derecho comparado, (núm. 136, 2013), pp. 165-199.

${ }^{25}$ Vid. una presentación muy útil en Martín Casals, M., Divorce Mediation in Europe: An Introductory Outline, Journal electronical comparative law,(vol. 9.2, julio 2005), http://www.ejcl.org/92/art92-2.html 
lares, que abordaba la mediación en el ámbito del derecho administrativo. Pero, posiblemente, la Recomendación de mayor calado es la Recomendación 10/2002, del Comité de Ministros a los estados miembros, sobre mediación en asuntos civiles ${ }^{26}$. Da lugar a iniciativas en diferentes países europeos como Bélgica o Austria, que aprueban leyes específicas de mediación civil o mercantil, y, añadiríamos, incide en una progresiva concienciación en las administraciones de todos los ámbitos.

De hecho, la Unión Europea ya había visibilizado de manera firme su implicación a partir de las Conclusiones del Consejo Europeo de Tampere en 199927, si bien un año antes (y no parece una mera casualidad que coincida temporalmente con la Recomendación 1/1998) el Plan de Acción del Consejo y de la Comisión sobre la mejor manera de aplicar las Disposiciones del Tratado de Ámsterdam relativas a la creación de un Espacio de libertad, seguridad y justicia se refería a la mediación familiar ${ }^{28}$.

El siguiente paso es la elaboración del Libro Verde sobre las modalidades alternativas de solución de conflictos en el ámbito del derecho civil y mercantil ${ }^{29}$. El Libro Verde serviría para constatar, a partir de las numerosas respuestas recibidas a un cuestionario previo, la muy desigual implantación de los ADR en los países europeos $^{30}$; también identificó las diferentes modalidades de ADR y sentó las Bases de la futura Directiva al pronunciarse sobre materias como la calidad, la eficacia de los acuerdos adoptados o la confidencialidad. Además, el Libro Verde visibilizó las iniciativas ya adoptadas en el ámbito del derecho de familia, consumo y relaciones laborales. Supuso una inflexión en los objetivos de la UE y su lectura todavía resulta sumamente útil 12 años después.

${ }^{26}$ Como ha hecho notar con lucidez Macho, "Origen y evolución de la mediación...”, cit., p. 978, esta Recomendación "es el símbolo de la etapa que los Estados europeos han estado experimentando con ese método de resolución de disputas durante los últimos años: la regulación completa de la mediación en normas propias, todo ello con el fin de utilizar este ADR, ya no sólo en el ámbito familiar, sino en el conjunto de materias que constituyen el derecho privado".

${ }^{27} \mathrm{http}: / /$ www.europarl.europa.eu/summits/tam_es.htm

${ }^{28}$ http://eur-lex.europa.eu/legal-content/ES/TXT/?uri=CELEX:31999Y0123(01). Indica, entre las Medidas que deberían adoptarse en el plazo de 5 años en el Apartado "Cooperación Judicial en materia civil": "Estudio de la posibilidad de elaborar soluciones no judiciales de las controversias, haciendo especial referencia a los conflictos familiares transnacionales. En este contexto, deberá estudiarse la posibilidad de mediación para resolución de conflictos familiares" [núm.41b)].

${ }^{29} \mathrm{http}: / /$ ec.europa.eu/civiljustice/adr/adr_ec_code_conduct_es.pdf Para situar los antecedentes, Martín Diz, F., "Alternativas extrajudiciales para la resolución de conflictos civiles y mercantiles: perspectivas comunitarias", La Ley, (núm. 3, 2006), pp. 1637-1654. También Andrés Ciurana, B., "La mediación civil y mercantil: Una asignatura pendiente en España. (a propósito de la propuesta de Directiva sobre ciertos aspectos de la mediación en asuntos civiles y mercantiles)", Actualidad Jurídica Uría Menéndez, (núm. 12-2005) http://www.uria.com/documentos/publicaciones/1470/documento/art4.pdf?id=2067

${ }^{30}$ Ortuño, P., "Libro verde sobre las modalidades alternativas de resolución de conflictos en el ámbito civil y mercantil de 19 de abril de 2002 de la Comisión de las Comunidades Europeas", Revista Iuris-La Ley, (núm. 77, nov. 2003), pp. 42 y ss. 
Por último, nuestro recorrido por los materiales previos a la DCAM debe completarse con una iniciativa muy interesante: el Código de conducta europeo para mediadores ${ }^{31}$, publicado en el 2004.

\subsubsection{La Directiva 2008/52/UE ¿Qué preocupaba al legislador europeo?}

Tras el análisis del Libro Verde, el título de la Directiva es suficiente o elocuentemente claro: por un lado se circunscribe al ADR-mediación; por el otro no se pretende una regulación in totum, sino de "ciertos aspectos" que se consideran esenciales para la implantación efectiva de la figura: específicamente, la calidad (art. 4) -en otras palabras, la solvente formación del profesional que debe conducirla-; el carácter ejecutivo de los acuerdos resultantes (art. 6) -pues en defecto de algún mecanismo que los convierta en ejecutivos, pese al principio del pacta sunt servanda, el procedimiento no resulta atractivo y alguna parte puede, incluso, considerarlos, si le interesa, papel mojado-; la confidencialidad (art. 7); y el efecto de la mediación sobre los plazos de caducidad y prescripción (art. 8). El Considerando 7 la define como una "legislación marco". Aunque se predica para litigios transfronterizos, el Considerando 8 recuerda que "nada debe impedir que los Estados miembros apliquen dichas disposiciones también a procedimientos de carácter nacional" ${ }^{2}$.

\subsubsection{La constante atención comunitaria}

La apuesta de la UE por la mediación no sólo se traduce en la Directiva 2008/52/UE o, más recientemente, en las Directivas de consumo; también en Directivas sectoriales. Baste recordar el art. 39 de la Directiva 2014/17/UE del Parlamento Europeo y del Consejo, de 4 de febrero de 2014, sobre los contratos de crédito celebrados con los consumidores para bienes inmuebles de uso residen-

\footnotetext{
${ }^{31}$ http://ec.europa.eu/civiljustice/adr/adr_ec_code_conduct_es.pdf. Incorpora una interesante definición de mediación, en la línea de las que hemos apuntado en el texto: "A efectos del Código de conducta, se entenderá por mediación cualquier procedimiento, con independencia de cómo se denomine o a él se refiera, en el que dos o más partes en un conflicto de intereses acuerden voluntariamente intentar resolverlo con la asistencia de un tercero, denominado en lo sucesivo, "el mediador"'.

${ }^{32}$ Como bibliografía útil, Díez Riaza, S., "El contrato de mediación civil y mercantil”, en Díez Riaza, S. y Gisbert Pomata, M., El Contrato de mediación y el acuerdo de mediación civil y mercantil, Civitas Thomson Reuters, Cizur Menor, 2014, p. 22 ss.; Arias Rodríguez, J. M., "Reflexiones acerca de la Directiva 2008/52/CE sobre ciertos aspectos de la mediación en asuntos civiles y mercantiles", Poder Judicial, (núm. 88, 2009), p. 166 ss.; Barona Vilar, S., "Incorporación de la mediación civil y mercantil en el ordenamiento jurídico español de la Directiva 2008/52 al Real Decreto-ley de 5/2012, de 5 de marzo, de mediación en asuntos civiles y mercantiles", en Esplugues Mota, C. y Palao Moreno, G., Nuevas fronteras del derecho de la Unión Europea. Liber amicorum José Luis Iglesias Buhigues, Tirant lo Blanch, Valencia, 2012, pp. 379. 394. También, Fernández Carron, C., "La Directiva de Mediación y su trasposición al derecho español", en Oliva Santos, A. de y Calderón Cuadrado, $\mathrm{M}^{\mathrm{a}} \mathrm{P}$. (dirs.), La armonización del Derecho procesal tras el Tratado de Lisboa, Thomson Reuters Aranzadi, Cizur Menor, 2012, pp. 325-397.
} 
cial $^{33}$. Asimismo, tras la aprobación de la DCAM, hay que destacar la Resolución del Parlamento Europeo, de 13 de septiembre de 2011, sobre la aplicación de la Directiva sobre la mediación en los Estados miembros, su impacto en la mediación y su aceptación por los Tribunales ${ }^{34}$. Es una nueva declaración a favor de la mediación y destaca el éxito de algunas acciones nacionales, como los incentivos económicos adoptados por Rumanía o la obligatoriedad establecida en Italia. Asimismo, aboga por un mayor número de acciones de fomento de la mediación y por el establecimiento de normas comunes para acceder a la profesión de mediador ${ }^{35}$.

Esta Resolución -oficial- anticipa, sin lugar a dudas, futuras acciones públicas. Pero, a nuestro juicio, lo más interesante en los últimos años a nivel comunitario han sido los estudios encargados desde diversos departamentos comunitarios y que han tenido eco en nuestro país. Así, el Informe sobre la cuantificación del no uso de la mediación en Europa ${ }^{36}$, el Análisis sobre el empleo efectivo de la mediación entre las empresas ${ }^{37}$, la atención a la mirada de los jueces ante la aplicación de la Directiva $^{38}$ o el Estudio "'Rebooting' the Mediation Directive: Assessing the Limi-

33 “Artículo 39. Mecanismos de resolución de litigios. 1. Los Estados miembros velarán por el establecimiento de procedimientos adecuados y efectivos de reclamación y recurso para la resolución extrajudicial de los litigios de los consumidores con prestamistas, intermediarios de crédito y representantes designados en relación con contratos de crédito, valiéndose, si procede, de organismos ya existentes. Los Estados miembros velarán por que tales procedimientos se apliquen a los prestamistas y los intermediarios de crédito y cubran las actividades de los representantes designados. 2. Los Estados miembros exigirán a los organismos que hayan tomado parte en la resolución extrajudicial de los litigios de los consumidores que cooperen de modo que puedan resolverse los conflictos transfronterizos sobre contratos de crédito". Sobre dicha Directiva, Díaz Alabart, S. (dir.) y Represa Polo, $\mathrm{M}^{2}$ P. (coord.), La protección del consumidor en los créditos hipotecarios (Directiva 2014/17/UE), Reus, Madrid, 2015 y Lauroba Lacasa, E. "La Directiva: 2014/17/UE... sobre los contratos de crédito celebrados con los consumidores para bienes inmuebles de uso residencial: ¿El impulso adecuado, el impulso deseado o el impulso asumible?" en Barral, I. y Tornos, J. (dirs.), Vivienda y crisis: ensayando soluciones, Decanato Autonómico de los Registradores de la Propiedad y Mercantiles de Cataluña Servicio de Estudios Registrales de Cataluña, Barcelona, 2015, pp. 153-167.

${ }^{34} \mathrm{http} / / /$ eur-lex.europa.eu/legal-content/ES/TXT/?uri=CELEX:52011IP0361

${ }^{35}$ De la Resolución, breve, vale la pena transcribir el punto 17, "[El Parlamento europeo] Señala que las soluciones que resultan de la mediación y que se han establecido entre las partes no podrían ser dictaminadas por un juez ni por un jurado; opina, por tanto, que es más probable que a través de la mediación se alcance un resultado satisfactorio para todas las partes; indica que, debido a ello, hay más posibilidades de que se acepte este tipo de acuerdo y que el cumplimiento de estos acuerdos de mediación suele ser muy elevado.

${ }^{36}$ Palo, G. de, Quantifying the Cost of non using Mediation- A Data Analysis, Parlamento europeo, Dirección General de Política interna-Departamento de Derechos de los ciudadanos y asuntos constitucionales, 2010. http://www.europarl.europa.eu/document/activities/cont/201105/20110518ATT19592/20110518 ATT19592EN.pdf

${ }^{37}$ Tilman, V., "Lessons learnt from the implementation of the EU Mediation Directive: the business perspective", informe encargado por el Comité de Asuntos Jurídicos del Parlamento europeo, y entregado en abril 2011, http://www.europarl.europa.eu/document/activities/cont/201105/20110518ATT19584/20 110518ATT19584EN.pdf

${ }^{38}$ Verougstraete, I., "Lessons learned From Implementation of the Mediation Directive. The Judge's Point of view, http://www.europarl.europa.eu/RegData/etudes/note/join/2011/453169/IPOL-JURI_ NT(2011)453169_EN.pdf 
ted Impact of its Implementation and Proposing Measures to Increase the Number of Mediations in the EU"39, liderado por el profesor Giuseppe de Palo -quien también había sido responsable del análisis citado supra sobre los costes de no usar la mediación-. Dicho estudio, tras identificar y deplorar la escasa implantación de la mediación tras la Directiva 2008/52/UE, propone nuevas medidas para su arraigo real en la UE. En pocas palabras, es una loa de la instauración de la mediación obligatoria, con el referente (próximo para los autores) de la experiencia italiana ${ }^{40}$. Resulta especialmente ilustrativa la mención a la EU Mediation paradox o, en otras palabras, a ¿cómo es posible que pese a las ventajas contrastadas de la mediación desde cualesquiera perspectivas, siga utilizándose tan poco? ${ }^{41}$

\subsection{La situación en España}

En España menudean, desde la primera década del siglo XXI, las leyes autonómicas de mediación, centradas, en una primera etapa, en la mediación familiar. Se les sumará, como norma general, la estatal en el 2012. Podemos anticipar que se centran en objetos diferentes. Obviamente, son objetos conexos, pero no coincidentes.

\subsubsection{El empeño estatal}

\section{A. LA ATENCIÓN TANGENCIAL A LA MEDIACIÓN FAMILIAR}

Solemos comentar que no existe una legislación específica sobre mediación familiar en el ámbito estatal. Ciertamente, la DF $3^{a}$ de la Ley 15/2005, de 8 de julio, por la que se modifican el Código Civil y la Ley de Enjuiciamiento Civil en materia de separación y divorcio señalaba:

"El Gobierno remitirá a las Cortes un proyecto de ley sobre mediación basada en los principios establecidos en las disposiciones de la Unión Eu-

\footnotetext{
${ }^{30} \mathrm{http} / / /$ www.europarl.europa.eu/RegData/etudes/etudes/join/2014/493042/IPOL-JURI_ET(2014)493042_ EN.pdf

${ }^{40}$ Como se apunta ya en el resumen ejecutivo inicial: "Five and a half years since its adoption, the Mediation Directive (2008/52/EC) has not yet solved the 'EU Mediation Paradox'. Despite its proven and multiple benefits, mediation in civil and commercial matters is still used in less than $1 \%$ of the cases in the EU. This study, which solicited the views of up to 816 experts from all over Europe, clearly shows that this disappointing performance results from weak pro mediation policies, whether legislative or promotional, in almost all of the $28 \mathrm{Member}$ States. The experts strongly supported a number of proposed nonlegislative measures that could promote mediation development. But more fundamentally, the majority view of these experts suggests that introducing a 'mitigated' form of mandatory mediation may be the only way to make mediation eventually happens in the EU".

${ }^{41}$ De Palo, G. y Canessa, R., "Sleeping? comatose? Only mandatory consideration of Mediation can awake sleeping beauty in the European Union", Cardozo Journal of Conflict Resolution, (2015), pp. 713 730. http://cardozojcr.com/wp-content/uploads/2015/06/De-Palo-and-Canessa-Sleeping-Beauty2.pdf
} 


\section{Elena Lauroba}

ropea, y en todo caso en los de voluntariedad, imparcialidad, neutralidad y confidencialidad y en el respeto a los servicios de mediación creados por las Comunidades Autónomas".

Ese envío no se produjo. A día de hoy no existe una ley de mediación familiar estatal. Es verdad que si atendemos a la noción en abstracto de mediación, siempre podemos pensar en la Ley 5/2012 -que además es aplicable, pese a opiniones en sentido contrario, a las relaciones familiares-, pero todo hace pensar que, en la mens legislatoris, la Ley identificada en esa DF $3^{a}$ era una Ley de mediación familiar, como avala la mención a los servicios de mediación de las CCAA. Esa aparente dejadez o dejación por parte del legislador -en contraste con los voluntariosos esfuerzos de las Comunidades Autónomas- acaso obedezca a la convicción de que ya había incorporado las modificaciones precisas con las reformas de la LEC que introdujo la propia Ley 15/2005. Lo avala el hecho de que en la práctica -y así se apunta en la DF $3^{\mathrm{a}}$ - la mediación regulada por las CCAA está pensando en sus unidades de gestión y promoción (en otras palabras, en esa mediación "pública" tutelada por las administraciones). La reforma de la LEC es ajena a esos postulados. En concreto, debemos mencionar el art. $770.7^{\circ} \mathrm{LEC}$, que permite a las partes de común acuerdo solicitar la suspensión del proceso - de conformidad con el art. 19.4 LEC- para someterse a mediación y el art. $777.2^{\circ} \mathrm{LEC}$ que permite aportar, en los procesos promovidos de mutuo acuerdo o instados por una de las partes con el consentimiento de la otra, en el escrito por el que se promueve el procedimiento de separación o divorcio, los acuerdos adoptados en el procedimiento de mediación familiar. También el art. 771.1 LEC (ese "acuerdo de las partes") aunque nos parece menos concluyente.

\section{B. LOS ASUNTOS CIVILES Y MERCANTILES: LA LEY 5/20I2, DE 6 DE JULIO}

España traspuso con retraso la Directiva 2008/52/UE. Hubo un primer Anteproyecto en el 2010, elevado a proyecto, que decayó con el fin de la legislatura. Ante la interpelación de la UE (la "carta de emplazamiento", dirigida inicialmente a 9 países), y con el fin de evitar sanciones, el gobierno aprobó apresuradamente el RD 5/2012. Luego vendría la Ley 5/2012, de 6 de julio.

La LMACM se estructura en cinco Títulos: Disposiciones generales (Título I); Principios informadores de la mediación (II); Estatuto del mediador (III); Procedimiento de mediación (IV); Ejecución de los acuerdos (V). Un total de 27 artículos; 4 Disposiciones Adicionales; 1 Disposición Derogatoria (la necesaria derogación del RDL 5/2012) y 10 Disposiciones Finales (entre las que destacar la DF $3^{\mathrm{a}}$, que reforma numerosos preceptos de la LEC).

Pese a su extensión, la LMACM no pretende una regulación in totum. Como recordaba el magistrado Ortuño, "no estamos, ni mucho menos, ante una "ley 
integral" sobre la mediación en el sentido de que no se pretende regular todas sus facetas (...). La opción del legislador ha sido la de dejar abiertos muchos interrogantes para que la experiencia práctica vaya consolidándose y se puedan sopesar con claridad las diversas opciones que la realidad ponga sobre la mesa" ${ }^{\prime 2}$.

Como en toda aproximación crítica a un texto normativo, pueden identificarse aspectos perfectibles. No es casualidad que varios estudios sobre la norma -muy solventes- sucumban a la tentación de hablar de "Luces y sombras". Baste señalar la definición de mediación ${ }^{43}$, que evoca una facilona adaptación de la construcción de la Directiva 2008/52/UE. Pero la LMACM incorpora aspectos valiosos. Queremos destacar aquí dos: por un lado, la regulación de la ejecutividad de los acuerdos en el Título V -tras el pánico que supuso el Anteproyecto del 2010, que consideraba ejecutables los acuerdos tout court- ${ }^{44}$. Por el otro lado, la fijación de la duración del procedimiento. Cuando el legislador establece que "La duración del procedimiento de mediación será lo más breve posible y sus actuaciones se concentrarán en el mínimo número de sesiones" (art. 20) uno tiene la impresión de que ha intuido cuál es la esencia de la figura.

Hemos hablado del deseo colectivo de contar con una ley estatal, pero probablemente la aprobación del Reglamento de desarrollo generó todavía mayor expectación. Tanto en las Recomendaciones del Libro Blanco de la Mediación en Cataluña como en las conclusiones del multitudinario Simposio celebrado en Madrid en septiembre del 2013, organizado por GEMME y con el patrocinio de la mayoría de colegios profesionales jurídicos, se pedía su pronta aprobación. Existía la convicción de que iba a proporcionar las coordinadas prácticas adecuadas para un impulso real de la mediación.

El RD 980/2013, de 13 de diciembre, por el que se desarrollan determinados aspectos de la Ley 5/2012, de 6 de julio, de mediación en asuntos civiles y mercantiles, de algún modo cierra el círculo normativo: en el propio título se habla de "determinados aspectos", esto es, se enlaza directamente con esos "ciertos aspectos" en la terminología y/o la acotación de la Directiva 2008/52/UE. Pero los aspectos determinados sólo coinciden parcialmente con los ciertos (básicamente la

\footnotetext{
${ }^{42}$ Ortuño, P., “Apuntes críticos...”, cit., p. 50. vid. García Villaluenga, L. y Vázquez De Castro, E., "La mediación civil en España: luces y sombras de un marco normativo", Política y Sociedad, (vol. 50, núm. 11, 2013); Iglesias Canle, I. C., "La mediación civil en España tras la Ley 5/2012, de 6 de julio, de mediación en asuntos civiles y mercantiles", en Iglesias Canle, I. C., Mediación, justicia y Unión Europea, Tirant lo Blanch, Valencia, 2014, pp. 109-124.

${ }^{43}$ Ortuño, P., "Comentario al artículo 1", en Castillejo Manzanares, R. (dir.) y Alonso Salgado, C. y Rodríguez Alvarez, A. (coords.), Comentario a la Ley 5/2012, de Mediación en asuntos civiles y mercantiles, Tirant lo Blanch, Valencia, 2013.

${ }^{44}$ Vid. al respecto Díez Riaza, S. y Gisbert Pomata, M., El Contrato de mediación y el acuerdo de mediación civil y mercantil, cit.; también Azcárraga Monzonís, C., "Impulso de la mediación en Europa y España y ejecución de acuerdos de mediación en la Unión europea como documentos públicos con fuerza ejecutiva", Revista electrónica de estudios internacionales, (2013), www.reei.org
} 


\section{Elena Lauroba}

formación), pues para el Reglamento los otros aspectos relevantes eran el registro de mediadores e instituciones de mediación; el seguro de responsabilidad civil y una escueta presentación del procedimiento simplificado de mediación por medios electrónicos. De hecho, el Reglamento se había demorado -y generado esa ansiosa espera- básicamente por el debate sobre la duración de la formación, que osciló desde las 40 horas en un borrador inicial (a imagen de la formación en los países anglosajones donde, no obstante, las coordenadas eran otras) hasta las 100 horas del texto vigente.

Podemos afirmar a día de hoy que la fijación de la duración de la formación tuvo algo de lotería o subasta, con contrastadas opiniones en puja incansable. Además, la demora sirvió para que se incorporasen casi subrepticiamente los mediadores concursales (en los borradores del Reglamento que circularon durante las semanas anteriores a la publicación, no parecía ninguna mención). Estos mediadores sólo tienen de mediadores stricto sensu la denominación y una obligada formación en técnicas de mediación, que muchos administradores concursales, obligados a reciclarse, consideran innecesaria ${ }^{45}$.

\subsubsection{La apuesta autonómica: de la mediación familiar al derecho privado y más allá}

Ya hemos apuntado cómo la temprana Recomendación número R (98) 1 del Comité de Ministros del Consejo de Europa a los Estados miembros constituyó un impulso relevante para la implantación de la mediación familiar en diversos territorios del Estado español. La primera Comunidad que se dotó de legislación fue Cataluña, con la Ley 1/2001, de 15 de marzo, de mediación familiar -aprobada por unanimidad y desarrollada por el Reglamento del $2002^{46}$-. Sin embargo, ya el art. 79.2 Codi de Família (ley 9/1998, de 15 de julio) mencionaba la mediación y -sobre todo-, la DF $3^{a}$ de dicha ley establecía que el legislador catalán debía presentar en el Parlamento un Proyecto de ley regulador de la mediación familiar ${ }^{47}$. En cumplimiento de esta prescripción, se llegó a presentar un Proyecto de Ley de mediación familiar, que decayó al convocarse elecciones en $1999^{48}$.

${ }^{45}$ Sobre la figura, vid. Aznar Giner, E., Mediación concursal. Los acuerdos extrajudiciales de pago, $2^{\mathrm{a}}$ ed., Tirant lo Blanch, Valencia, 2016.

${ }^{46}$ Decreto 139/2002, de 14 de mayo, por el cual se aprueba el Reglamento de la Ley 1/2001, de mediación familiar de Catalunya (DOGC núm. 3641, de 23 de mayo).

${ }^{47}$ La futura ley, señalaba la DF $3^{\text {a }}$, debía ajustarse a las bases siguientes: a) Confidencialidad absoluta del contenido de las sesiones de mediación; b) libertad de las partes de apartarse o desistir de la mediación en cualquier momento; c) aprobación judicial de los acuerdos asumidos en la mediación; d) Duración máxima del proceso de mediación limitada a tres meses, prorrogables por el mismo tiempo a petición del mediador o mediadora. Martín Casals, M., "Comentario a la Disposición Final Tercera", en Egea, J. y Ferrer, J. (dirs.), Lamarca, A. y Ruisánchez, C. (coords.), Comentaris al Codi de Família, a la llei d'unions estables de parella $i$ a la llei de situacions convivencials d'ajuda mútua, Tecnos, Madrid, 2000, p. 1131 ss.

${ }^{48}$ Butlletí Oficial del Parlament de Catalunya, núm. 384, 29.3.1999, pp. 31721-31726. 
La ley del 2001 constituyó un referente para otras CC.AA., que aprobaron diferentes leyes a imagen de la catalana, pero que incrementaron los supuestos susceptibles de mediación familiar. Frente al ámbito acotado de la ley catalana, que circunscribía la mediación familiar a los conflictos estrictos de pareja y de ejercicio de la potestad respecto de los hijos comunes ${ }^{49}$, las sucesivas leyes autonómicas identifican otros conflictos. Así, la ley valenciana (2001) mencionaba los conflictos derivados de la empresa familiar ${ }^{50}$, la ley de mediación canaria (2003) incluía los conflictos entre personas adoptadas y sus familias biológicas o adoptivas ${ }^{51} \mathrm{o}$, como último ejemplo, la ley asturiana (2007) mencionaba también los alimentos ente parientes.

A día de hoy, tienen ley de mediación las comunidades de Andalucía ${ }^{52}$; Aragón $^{53}$, Asturias ${ }^{54}$, Canarias ${ }^{55}$, Cantabria ${ }^{56}$, Castilla La Mancha ${ }^{57}$, Castilla y León ${ }^{58}$, Cataluña ${ }^{59}$, Comunitat valenciana ${ }^{60}$, Galicia ${ }^{61}$; Illes Balears ${ }^{62}$; Comunidad de Madrid $^{63}$ y País Vasco ${ }^{64,65}$. Básicamente desarrollan la mediación familiar, con dos excepciones: las leyes catalana y cántabra. Aunque algún autor se ha preguntado

${ }^{49}$ Se hablaba de los conflictos de "las personas unidas por un vínculo matrimonial o que forman una unión estable de pareja y las que, sin formar una unión estable tenían hijos comunes" (art. 5). Con vocación residual se mencionaban los conflictos por razón de alimentos entre parientes o de instituciones tutelares".

${ }^{50}$ Art. 13.1.a) 6 Ley 7/2001, de 26 de noviembre, reguladora de la Mediación Familiar en el ámbito de la Comunidad valenciana.

${ }^{51}$ Art. 3 Ley 15/2003, de 8 de abril, de la mediación familiar.

${ }^{52}$ Ley 1/2009, de 27 de febrero, reguladora de la Mediación Familiar en la Comunidad Autónoma de Andalucía; Decreto 37/2012, de 21 de febrero, por el que se aprueba el Reglamento de Desarrollo de la Ley 1/2009, de 27 de febrero, reguladora de la Mediación Familiar en la comunidad Autónoma de Andalucía.

${ }^{53}$ Ley 9/2011, de 24 de marzo, de mediación familiar de Aragón.

${ }^{54}$ Ley del Principado de Asturias 3/2007, de 23 de marzo, de mediación familiar.

${ }^{55}$ Ley 15/2003, de 8 de abril, de mediación familiar (modificada por la ley 3/2005, de 23 de junio).

${ }^{56}$ Ley $1 / 2011$, de 28 de marzo, de Mediación de la comunidad autónoma de Cantabria.

${ }^{57}$ Ley 4/2005, de 24 de mayo, del Servicio Social especializado de Mediación Familiar.

${ }^{58}$ Ley 1/2006, de 6 de abril, de mediación familiar de Castilla y León.

${ }^{59}$ Ley 15/2009, de 22 de julio, de mediación en el ámbito del derecho privado.

${ }^{60}$ Ley 7/2001, de 26 de noviembre, reguladora de la mediación familiar en el ámbito de la Comunidad Valenciana.

${ }^{61}$ Ley 4/2001, de 31 de mayo, reguladora de la mediación familiar.

${ }^{62}$ Ley 14/2010, de 9 de diciembre, de Mediación familiar de las Illes Balears.

${ }^{63}$ Ley 1/2007, de 21 de febrero, de Mediación familiar en la comunidad de Madrid.

${ }^{64}$ Ley $1 / 2008$, de 8 de febrero, de mediación familiar.

${ }^{65}$ Se pueden consultar en http://www.poderjudicial.es/cgpj/es/Temas/Mediacion/Normativa-y-jurisprudencia/Leyes-Autonomicas/. Una aséptica visión comparatista, sistemática, en Duplá Marín, Mª . T. (coord.), El régimen jurídico de la mediación familiar en España. Análisis de la normativa autonómica, Editorial Andavira, Santiago de Compostela, 2012. 
sobre los posibles aspectos superfluos de la multiplicación de normas autonómicas, han contribuido a consolidar la institución ${ }^{66}$.

El caso catalán revela la vertiginosa implantación de la mediación en nuestro país, o la inquietud que no cesa. A la vista de las sucesivas leyes autonómicas, así como de las experiencias europeas, estadounidenses y canadienses, el legislador catalán estimó que su normativa era restrictiva en exceso. Además, existía la convicción de que era preciso superar el marco de la familia para entrar en el de la comunidad. Se comenzó, por tanto, a elaborar una nueva ley, que tenía presentes los materiales que habían dado lugar a la Directiva 2008/52/CE.

En un principio se habló de una Ley de Mediación familiar y comunitaria, pero tras la información pública se adoptó la denominación vigente: Ley de mediación en el ámbito del derecho privado (Ley 15/2009, de 22 de julio) ${ }^{67}$. Pese al título, la regulación se focaliza en los conflictos con un elemento relacional determinante. Un primer apartado del art. 2 se dedica a cualesquiera conflictos en el ámbito familiar $^{68}$, desde los que versan sobre el cuidado de las personas mayores o dependientes con las que exista una relación de parentesco hasta los conflictos derivados de la liquidación de bienes en situación de comunidad entre los miembros

${ }^{66}$ Ortíz Pradillo, J. C., "La mediación como método de solución de conflictos en el estado de las autonomías" en Iglesias Canle, I. C., Mediación, justicia y Unión Europea, Tirant lo Blanch, Valencia, 2014.

${ }^{67}$ Lauroba, E., "La apuesta del legislador catalán: de la mediación familiar a la mediación en el ámbito del Derecho privado", en Lauroba, E., Barral, I. y Viola, I., Materiales Jurídicos del Libro Blanco de la mediación en Catalunya, Generalitat de Catalunya, Barcelona, 2011, pp. 21-31.

68 "1. La mediación familiar comprende de forma específica: a) Las materias reguladas por el Código civil de Cataluña que en situaciones de nulidad matrimonial, separación o divorcio deban ser acordadas en el correspondiente convenio regulador.// b) Los acuerdos a alcanzar por las parejas estables al romperse la convivencia.// c) La liquidación de los regímenes económicos matrimoniales.// d) Los elementos de naturaleza dispositiva en materia de filiación, adopción y acogida, así como las situaciones que surjan entre la persona adoptada y su familia biológica o entre los padres biológicos y los adoptantes, como consecuencia de haber ejercido el derecho a conocer los datos biológicos.//e) Los conflictos derivados del ejercicio de la potestad parental y del régimen y forma de ejercicio de la custodia de los hijos // f) Los conflictos relativos a la comunicación y relación entre progenitores, descendientes, abuelos, nietos y demás parientes y personas del ámbito familiar.//g) Los conflictos relativos a la obligación de alimentos entre parientes.// h) Los conflictos sobre el cuidado de las personas mayores o dependientes con las que exista una relación de parentesco.// i) Las materias que sean objeto de acuerdo por los interesados en las situaciones de crisis familiares, si el supuesto presenta vínculos con más de un ordenamiento jurídico.//j) Los conflictos familiares entre personas de nacionalidad española y personas de otras nacionalidades residentes en el Estado español.// k) Los conflictos familiares entre personas de la misma nacionalidad pero diferente de la española residentes en el Estado español.//l) Los conflictos familiares entre personas de diferentes nacionalidades distintas a la española residentes en el Estado español.// m) Los requerimientos de cooperación internacional en materia de derecho de familia.// n) La liquidación de bienes en situación de comunidad entre los miembros de una familia.// o) Las cuestiones relacionales derivadas de la sucesión de una persona.// p) Los conflictos surgidos en las relaciones convivenciales de ayuda mutua.//q) Los aspectos convivenciales en las acogidas de ancianos, así como en los conflictos para la elección de tutores, el establecimiento del régimen de visitas a las personas incapacitadas y las cuestiones económicas derivadas del ejercicio de la tutela o de la guarda de hecho.//r) Los conflictos de relación entre personas surgidos en el seno de la empresa familiar // s) Cualquier otro conflicto en el ámbito del derecho de la persona y de la familia susceptible de ser planteado judicialmente." 
de una familia, por escoger dos supuestos. El legislador pretendía que no quedara un solo supuesto "amediable". Lo ratifica el apartados), que menciona cualquier otro "susceptible de ser planteado judicialmente", por si todavía quedaba algún resquicio. Y es que, pese a una meticulosidad acaso excesiva, siempre quedan supuestos por identificar. Y pensamos como caso más visible en la problemática de las familias reconstituidas, que contempla el art. 236-14 CCCat.

Pero el aspecto más interesante es el art. 2.2, que atiende a "cualquier tipo de cuestión o pretensión en materia de derecho privado que pueda conocerse en un proceso judicial y que se caracterice porque se haya roto la comunicación personal entre las partes, si estas deben mantener relaciones en el futuro". Acto seguido, identifica:

a) Los conflictos relacionales surgidos en el ámbito de las asociaciones y fundaciones.

b) Los conflictos relacionales en el ámbito de la propiedad horizontal y en la organización de la vida ordinaria de las urbanizaciones.

c) Las diferencias graves en el ámbito de la convivencia ciudadana o social, para evitar la iniciación de litigios ante los juzgados.

d) Los conflictos derivados de una diferente interpretación de la realidad debido a la coexistencia de las diversas culturas presentes en Cataluña.

e) Cualquier otro conflicto de carácter privado en que las partes deban mantener relaciones personales en el futuro, si, razonablemente, aún puede evitarse la iniciación de un litigio ante los juzgados o puede favorecerse la transacción.

Hemos transcrito el apartado porque, a nuestro juicio, es muy útil para formular dos reflexiones. En primer lugar nos permite identificar, en el ámbito estricto del derecho civil, unos supuestos concretos (valioso pedagógicamente). Y con un máximo común denominador: el aspecto relacional. Esta era la principal preocupación del legislador catalán, asesorado por expertos que consideran el mantenimiento de las relaciones como uno de los efectos benéficos -si no el principal- de la mediación. Esta preocupación, que también existe en la LMACM, no es sin embargo consustancial a sus propósitos. La LMACM también atiende a la mediación como solución óptima para, por ejemplo, un conflicto sobre la resolución de un contrato de compraventa o de servicios, esto es, para un conflicto entre dos partes que no pretenden volver a relacionarse nunca más. Este supuesto no queda excluido de la ley catalana, pero no parece nuclear, lo que nos permite deslindar mejor los ámbitos respectivos de ambas normas.

Si la ley catalana pretende atender al ámbito del derecho privado -y se vaticina que será seguida por otras normas autónomas ${ }^{69}-$, la Ley 1/2011, de 28 de

${ }^{69}$ Ortíz Pradillo, "La mediación como método de solución de conflictos en el Estado de las autonomías", cit., p. 83. 


\section{Elena Lauroba}

marzo, de Mediación de la Comunidad Autónoma de Cantabria es todavía más ambiciosa. Como declara en la Exposición de Motivos, se inspira en la ley catalana del 2009, "pero tratando de superarla y dar un ámbito absolutamente integral a esta institución [la mediación]". Por ello, afecta también a la mediación en el ámbito del derecho administrativo o del derecho laboral.

Hechas estas consideraciones, hay un segundo aspecto que debemos destacar. Las regulaciones autonómicas se centran, básicamente, en la "mediación pública", entendida no como mediación en el ámbito del derecho público, sino como mediación privada gestionada por una administración pública. Como ejemplo evidente, la ley catalana. Cotejemos, pese a una cierta evolución, las leyes del 2001 y del 2009. En la ley del 2001, la regulación se centraba en el Centro de Mediación en derecho de familia, regulado en el art. $2^{70}$. Era el principal gestor/impulsor de la institución, con la ayuda de los Colegios Profesionales-. La LMADP se centra desde el primer momento en la mediación como institución. En una lectura sistemática, el centro se contempla en el Capítulo IV (arts. 20-21) Dicho esto, el sesgo hacia la mediación "pública" se advierte en diversas normas como, por ejemplo, en la regulación del procedimiento (Capítulo III, Desarrollo de la mediación) que en realidad sólo afecta a las mediaciones que no son estrictamente privadas, como avala el art. 1071. También es sumamente ilustrativa la Disposición Adicional Segunda, que establece que los Principios recogidos en el Capítulo II (los principios identificadores de la mediación), son aplicables a todas las personas mediadoras que lleven a cabo actuaciones de mediación para la resolución de conflictos en el ámbito familiar y en los restantes de derecho privado a que hace referencia la ley. Se remarca que les resulta aplicable el capítulo II, ergo los restantes capítulos pueden no afectarles. Y es que los mediadores no vinculados al centro no han de estar sujetos al régimen sancionador (capítulo V) o al régimen de recursos (capítulo VI). Estos capítulos muestran ese sesgo público que señalábamos supra.

La gestión por un organismo público conlleva, como consecuencia colateral, un procedimiento más rígido (con limitación, por ejemplo, del número de sesiones y su duración). Ese encorsetamiento va ligado, en buena medida, a la necesidad

70 "Artículo 2: Organización. Se crea el Centro de Mediación Familiar de Cataluña, entidad sin personalidad jurídica propia, adscrita al Departamento de Justicia, que tiene por objeto promover y administrar la mediación regulada por la presente Ley y facilitar que se pueda acceder a la misma // 2. El Centro de Mediación Familiar de Cataluña es el encargado de designar a la persona mediadora en las mediaciones que se solicitan a instancias de la autoridad judicial o de las personas interesadas. 3 (...)".

${ }^{71}$ Como se afirma en ocasiones, se puede decir más alto, pero no más claro: "Artículo 10: Ámbito de aplicación del procedimiento de mediación El procedimiento de mediación establecido por la presente ley es de aplicación: a) A las mediaciones familiares y demás materias de derecho civil desarrolladas por los mediadores designados por el órgano de mediación del departamento competente en materia de derecho civil. b) A las mediaciones familiares y demás materias de derecho civil desarrolladas por los mediadores designados por las entidades firmantes de convenios con el departamento competente en materia de derecho civil, si lo establece el propio convenio". 
de un cálculo tendencialmente objetivo de los gastos derivados de cada mediación (que la Administración ha de sufragar). La LMACM no tiene presentes ni esta perspectiva, ni las cortapisas que puede comportar, en una prueba más de la posible coexistencia armónica de las legislaciones de las autonomías y del estado.

\section{CONCLUSIONES}

A día de hoy, si no somos empecinadamente optimistas, un vistazo a las estadísticas sobre el recurso a la mediación obligan a pensar que el vaso está medio vacío. Los números publicados por el CGPJ de 2014 -los más recientes, a la hora de cerrar este trabajo- en relación a las mediaciones intrajudiciales hablan por sí solos ${ }^{72}$.

Mediación familiar:

Datos 2014. Comparativa 2013/2014

\begin{tabular}{|l|c|}
\hline DATOS ANUALES 2013 & \\
\hline TOTAL derivaciones realizadas & 5.116 \\
\hline TOTAL mediaciones efectuadas & 1.162 \\
\hline TOTAL mediaciones terminadas CON ACUERDO & 568 \\
& $48.8 \%$ \\
\hline TOTAL mediaciones terminadas SIN ACUERDO & 594 \\
\hline DATOS ANUALES 2014 & $51.11 \%$ \\
\hline TOTAL derivaciones realizadas & 6.101 \\
\hline TOTAL mediaciones efectuadas & 1.379 \\
\hline TOTAL mediaciones terminadas CON ACUERDO & 598 \\
\hline TOTAL mediaciones terminadas SIN ACUERDO & $43.36 \%$ \\
\hline
\end{tabular}

Estamos ante un porcentaje que bordea la anécdota si recordamos que la tasa de litigiosidad por cada 1000 habitantes era en el 2014 de 185,0, con el plus de que las mediaciones sin acuerdo superan las que concluyen con acuerdo, contestando un postulado generalmente defendido cuando se valora la utilidad de la mediación. Por eso no podemos compartir el moderado entusiasmo del CCPJ, cuando se felicita ante la progresiva implantación.

\footnotetext{
${ }^{72}$ http://www.poderjudicial.es/cgpj/es/Temas/Mediacion/Datos-estadisticos/Mediacion-intrajudicialen-Espana--datos-2014
} 
En relación con las mediaciones civiles no familiares, el resultado es todavía peor. Baste reproducir este cuadro:

\begin{tabular}{|l|c|c|}
\hline \multicolumn{2}{|c|}{2014} & \\
\hline TOTAL derivaciones realizadas & 549 & Porcentaje \\
\hline Total de mediaciones efectuadas & & \\
\hline Finalizadas con acuerdo & 37 & $31.09 \%$ \\
\hline Finalizadas sin acuerdo & 82 & $68.90 \%$ \\
\hline
\end{tabular}

De ahí que el propio CGPJ reconozca que "está costando que la mediación arraigue". La decepción es mayor cuando se advierte que las derivaciones a mediación de los juzgados en el 2014 había sido un 25 \% inferior al año anterior. Todo ello nos aboca, de nuevo, a la famosa paradoja que se denunciaba en la UE. A partir de aquí, nos permitimos algunas reflexiones, y algunas propuestas.

La adopción de la mediación pasa por la superación de dos hechos: el desconocimiento de la ciudadanía y la desconfianza de los abogados. A otro nivel, también por la mayor implicación de los jueces, o quizás por una implicación diferente.

La desconfianza de los abogados va ligada a la sensación de que es un instrumento que los relega, incluso que los hace prescindibles. Intuyen el mayor protagonismo de las partes como una jibarización de sus funciones. Debe, de alguna manera, superarse ese estado mental.

1. Para ello, se debe conseguir -y es una acción perfectamente identificada-que los abogados no encaren la mediación a partir de la asunción del rol de mediadores, sino a partir de la adecuada adquisición de las habilidades y competencias que conocemos - propias de la mediación- que les conviertan en adecuados asesores intervinientes en un proceso de mediación. A ellos les corresponde intervenir como abogados de las partes, a su lado -son sus clientes- en el mejor y más provechoso desarrollo del proceso (y la mejor consecución de sus intereses). Desde esta perspectiva, la formación en mediación será provechosa, también en términos económicos. Y no les quitará trabajo. Como señalaba un magistrado con buen humor, quien debe temer por la pérdida de trabajo ante la irrupción de la mediación no es el abogado, que sencillamente se implica en otro procedimiento para la gestión del conflicto, sino el juez, que ve que existe otra vía preferible a la jurisdiccional.

2. Otra medida importante, que puede facilitar la tarea de los abogados, pero que resulta útil para la sociedad en general, es la conformación de un corpus teórico relativo a la mediación y a los ADR en general. La existencia de una proliferación de trabajos y reflexiones sobre la materia, incluso si muy heterogéneos o poco leídos, consolida una disciplina. Y siempre incorpora datos que orientan sobre nuevas políticas de implementación, promoción o fomento. Baste mencionar el Libro Blanco de 
la Mediación en Cataluña, un trabajo de investigación en que se implicaron más de 100 investigadores de las universidades catalanas durante dos años, y que contó con el generoso patrocinio de la Obra Social La Caixa. Permitió identificar numerosas experiencias de mediación que hasta entonces no se conocían (con el consiguiente sentimiento de voluntarismo, si no de heroicidad, de sus impulsores, robinsones modernos $^{73}$ ). Saber de los esfuerzos del otro creó un sentimiento de red (y para muchos mediadores resultó vitamínico). La plasmación de esas iniciativas permitió obtener un scanner solvente de la realidad de la mediación en Cataluña en ámbitos tan diversos como la sanidad, la enseñanza, el consumo o la comunidad/ciudadanía; correlativamente conllevó la adopción de medidas que se han revelado efectivas ${ }^{74}$.

Otra iniciativa posterior, a nuestro juicio benéfica, fue la constitución de los Puntos Neutros [de Promoción de la] Pro Mediación (PNPM $\left.{ }^{75}\right)$, que con una metodología innovadora y entusiasta fueron capaces de crear, discutir y diseminar importantes documentos de trabajo sobre los Protocolos de derivación a mediación, la calidad y los códigos de buenas prácticas en la mediación y los posibles acciones de difusión de la mediación. Los esfuerzos de los PNPM han proporcionado unos materiales, a un tiempo rigurosos y pedagógicos (esto es, perfectamente inteligibles, que no es poco). Y confiamos en que los esfuerzos entusiastas de la CUEMYC ${ }^{76}$ también contribuyan a ese necesario fondo de teorización y de análisis. Frente al desespero ante la falta de mediaciones reales, la presencia continuada de la figura, el esfuerzo para la conformación de su saber (un saber reciente), ha de acabar dando frutos.

3. Queda la tarea de los jueces, que han sido impulsores destacados de la mediación, a partir de organizaciones como GEMME. Como ocurre con los restantes operadores jurídicos, encontramos entusiastas y escépticos, pero en general comparten una severa preocupación por una litigiosidad que crece exponencialmente y por la necesidad de tener que pronunciarse constantemente sobre asuntos que técnicamente se corresponden con la denominada "litigiosidad impropia". Creemos que la mejor manera de reconducirlos a las tareas que realmente les corresponden es mediante el diseño y la implantación de sistemas denominados multi-door. Ciertamente, en estos momentos, en nuestro país estamos empezando a hablar de justicia multi-door, denominación que se traduce, en la práctica, en la

${ }^{73}$ Más allá del ámbito del derecho privado, por ejemplo, el análisis del uso y consolidación de la mediación escolar es muy importante, entre otras cosas porque es un instrumento benéfico para una progresiva implantación de la mediación en la sociedad.

${ }^{74} \mathrm{El}$ éxito de la iniciativa se traduce en cifras concretas: a día de hoy consta que se han producido más de 20.000 "bajadas" del documento desde la web.

${ }^{75}$ Ortuño, P., "El impulso a la mediación en la experiencia de los PNPM", en Lauroba, E. y Ortuño, P., Mediación es Justicia. El impacto de la Ley 5/2012, de Mediación civil y mercantil, Huygens, Barcelona, 2014, pp. 3-13.

${ }^{76}$ Vid. García Villaluenga, L., "La enseñanza de la mediación en la Universidad: la CUEMYC. Un testimonio", en Lauroba, E. y Ortuño, P., Mediación es Justicia. El impacto de la Ley 5/2012, de Mediación civil y mercantil, cit., pp. 149-152. 


\section{Elena Lauroba}

incorporación, en numerosos juzgados de otros países -significativamente americanos, pero también, por ejemplo, australianos ${ }^{77}$ - de la denominada Multi-Door Dispute Resolution Division (Multi-Door), esto es, una unidad que tiene su sede en los propios juzgados y que pretende facilitar/indicar a las partes en conflicto cuál es el instrumento de ADR más adecuado para su gestión (mediación, coordinación parental, evaluación neutral...). No podemos desarrollar más esta fórmula, que nos resulta sumamente atractiva, pero sí destacar que el sistema multi-door no excluye a los tribunales de los conflictos del ámbito familiar, sólo los aleja de la sala de vistas. Es la unidad del propio juzgado la que calibra y decide, a la vista del conflicto singular, cuál es la/s opción/es más adecuada/s ${ }^{78}$. Vale la pena tener presente este hecho, porque despeja los reproches -ya puntuales, pero aún existentes- de que los ADR, al evitar la intervención jurisdiccional, pueden convertirse en un mecanismo en que impere la ley del más fuerte, o que facilita, sibilinamente, la consolidación de desigualdades. Una medida de este tipo supone consolidar el empleo de la mediación -que suele ser el punto de partida-, a la vez que asienta -creemos- una mayor confianza en la totalidad del sistema.

\section{Coda. Un apunte final}

Antes hemos mencionado el Libro Blanco de la Mediación en Cataluña como un ejemplo de trabajo de investigación útil para el fomento y la implementación de la mediación o, desde otra perspectiva conexa, para el arraigo de la institución en un territorio. Por ello queremos concluir recordando dos de sus Recomendaciones, que a día de hoy son, en su sencillez, si cabe todavía más necesarias.

"Recomendación n.3: Se recomienda, y se considera necesario, concienciar
a los máximos responsables del poder judicial de las ventajas y los benefi-
cios de la mediación para la gestión de determinados tipos de conflictos. La
derivación de conflictos a mediación permite a los jueces un mejor desa-
rollo de sus funciones, dado que pueden concentrarse en aquellos conflic-
tos que, por sus características, necesitan indefectiblemente su autoridad.
Conseguir que determinadas controversias se resuelvan mediante la media-

77 http://www.ncsc.org/sitecore/content/microsites/future-trends-2013/home/ /media/Microsites/Files/Future\%20Trends\%202013/06202013-Australias-Civil-Justice-System-Developing-a-Multi-OptionResponse.ashx

${ }^{78}$ Una concisa presentación en Martín Diz, F. La mediación: sistema complementario de administración de justicia, CGPJ, 2010, pp. 149-153. Como lúcida reflexión reciente, Ortuño, P., "Gestionar los conflictos familiares. Del monopolio jurisdiccional a las propuestas «multi-door», en El derecho de familia y los nuevos modelos de familia. Novedades doctrinales y Jurisprudencia. Libro Homenaje a Encarna Roca Trías, RJC-Thomson Reuters Aranzadi, 2014, pp. 85-93. 
ción mejora la resolución, en su conjunto, de los conflictos que llegan a los órganos jurisdiccionales.

$>$ Recomendación n.12: Se recomienda la facilitación y la exigencia de una formación rigurosa en mediación, ligada tanto a las especificidades de la metodología, como al ámbito sustantivo -los conflictos-. Solo con una formación completa, que aúne las vertientes teórica y práctica, se obtendrá un mediador profesionalmente competente y a la vez respetado socialmente $(\ldots)$ ".

\section{BIBLIOGRAFIA}

ALASTRUEY, R., "Argumentario sobre la búsqueda de soluciones negociadas en el proceso civil" [http://www.mediacion.icav.es/archivos/contenido/1055.pdf, última consulta 11.4.2016]

ANDRÉS CIURANA, B., "La mediación civil y mercantil: Una asignatura pendiente en España (a propósito de la propuesta de Directiva sobre ciertos aspectos de la mediación en asuntos civiles y mercantiles)", Actualidad Jurídica Uría Menéndez, (núm. 12, 2005).

ARIAS RODRÍGUEZ, J. M., "Reflexiones acerca de la Directiva 2008/52/CE sobre ciertos aspectos de la mediación en asuntos civiles y mercantiles", Revista del Poder Judicial, (núm.88, 2009), pp. 133-175.

AZCARRAGA MONZONÍS, C., "Impulso de la mediación en Europa y España y ejecución de acuerdos de mediación en la Unión europea como documentos públicos con fuerza ejecutiva", Revista electrónica de estudios internacionales, (2013), www.reei.org

AZNAR GINER, E., Mediación concursal: los acuerdos extrajudiciales de pago, $2^{\mathrm{a}}$ ed., Tirant lo Blanch, Valencia, 2016.

BARONA VILAR, S., "Integración de la mediación en el moderno concepto de Acces to Justice. Luces y sombras en Europa”, InDret, (núm. 4, 2014), http://www.indret.com/pdf/1092.pdf

BARONA VILAR, S., "Incorporación de la mediación civil y mercantil en el ordenamiento jurídico español. De la Directiva 2008/52 al Real Decretoley de 5/2012, de 5 de marzo, de mediación en asuntos civiles y mercantiles", en Esplugues Mota, C. y Palao Moreno, G., Nuevas fronteras del derecho de la Unión Europea. Liber amicorum José Luis Iglesias Buhigues, Tirant lo Blanch, Valencia, 2012, pp. 379-394.

BERNAL SAMPER, T. "La confidencialidad como principio rector e identificador de la mediación III", en Lauroba, E. y Ortuño, P., Mediación es Justicia. El impacto de la Ley 5/2012, de Mediación civil y mercantil, Huygens, Barcelona, 2014. 
CAVUOTO, E., "La nueva mediación obligatoria en Italia", en Iglesias Canle, I. C., Mediación, justicia y Unión Europea, Tirant lo Blanch, Valencia, 2014, pp. 299-310.

DE PALO, G. y CANESSA, R., "Sleeping? Comatose? Only mandatory consideration of Mediation can awake sleeping beauty in the European Union", Cardozo Journal of Conflict Resolution, (2015), pp. 713-730. http://cardozojcr.com/ wp-content/uploads/2015/06/De-Palo-and-Canessa-Sleeping-Beauty2.pdf

DÍEZ RIAZA, S. y GISBERT POMATA, M., El Contrato de mediación y el acuerdo de mediación civil y mercantil, Cizur Menor, Civitas Thomson Reuters, Cizur Menor, 2014.

DUPLÁ MARÍN, $\mathrm{M}^{\mathrm{a}} \mathrm{T}$. (coord.), El régimen jurídico de la mediación familiar en España. Análisis de la normativa autonómica, Andavira, Santiago de Compostela, 2012.

ESPLUGUES MOTA, C., "El régimen jurídico de la mediación civil y mercantil en conflictos transfronterizos en España tras la ley 5/2012, de 6 de julio", Boletín Mexicano de Derecho Comparado, (núm. 136, 2013), pp. 165-199 http:// biblio.juridicas.unam.mx/revista/pdf/DerechoComparado/136/art/art6.pdf

FERNÁNDEZ CARRON, C., "La Directiva de Mediación y su trasposición al derecho español", en Oliva Santos, A. de y Calderón Cuadrado, $\mathrm{M}^{\mathrm{a}} \mathrm{P}$. (dirs.), La armonización del Derecho procesal tras el Tratado de Lisboa, Thomson Reuters Aranzadi, Cizur Menor, 2012, pp. 325-397.

GARCÍA VILLALUENGA, L., "La enseñanza de la mediación en la Universidad: la CUEMYC. Un testimonio", en Lauroba, E. y Ortuño, P., Mediación es Justicia. El impacto de la Ley 5/2012, de Mediación civil y mercantil, Huygens, Barcelona, 2014, pp. 149-152.

GARCÍA VILLALUENGA, L. y VÁZQUEZ DE CASTRO, E., "La mediación civil en España: luces y sombras de un marco normativo", Política y Sociedad, (vol. 50 n. 1, 2013), pp. 71-98.

GINEBRA MOLINS, E. y TARABAL BOSCH, J., "Mediación obligatoria e inducción a la mediación", en Lauroba, E. y Ortuño, P., Mediación es Justicia. El impacto de la Ley 5/2012, de Mediación civil y mercantil, Huygens, Barcelona, 2014, pp. 227-234.

GINEBRA, E. y TARABAL, J., "La obligatoriedad de la mediación: derivada de la voluntad de las partes: las cláusulas de mediación", Indret, (núm. 4, 2013), http://www.raco.cat/index.php/InDret/article/viewFile/270125/357682

GUTIÉRREZ SANZ, $M^{a}$ R., "El procedimiento de mediación: transposición de la Directiva 2008/52/CE por la Ley 5/2012 de 6 de julio, de mediación en los asuntos civiles y mercantiles", en Hualde, T. (dir.) y Mestrot, M. (coord.), La mediación en asuntos civiles y mercantiles. La transposición de la Directiva 2008/52 en Francia y en España, La Ley, Madrid, 2013. 
IGLESIAS CANLE, I. C., "La mediación civil en España tras la Ley 5/2012, de 6 de julio, de mediación en asuntos civiles y mercantiles", en Iglesias Canle, I. C., Mediación, justicia y Unión Europea, Tirant lo Blanch, Valencia, 2014, pp. 109-124.

IMPAGNATIELLO, G., "La mediazione civile in Italia", en Iglesias Canle, I. C., Mediación, justicia y Unión Europea, Tirant lo Blanch, Valencia, 2014, pp. 157-183.

LAUROBA, E. "La mediación en Cataluña", en Ginés, N. (coord.), Familia del siglo XXI: algunas novedades del libro II del Código civil de Cataluña, J. M. Bosch, Barcelona, 2011, pp. 141-193.

LAUROBA, E., "La apuesta del legislador catalán: de la mediación familiar a la mediación en el ámbito del Derecho privado", en Lauroba, E., Barral, I. y Viola, I., Materiales Jurídicos del Libro Blanco de la mediación en Catalunya, Generalitat de Catalunya, Barcelona, 2011, pp. 21-31.

LAUROBA, E., BARRAL, I., TARABAL, J. y VIOLA, I., "La construcción institucional y jurídica de la mediación", Libro Blanco de la mediación en Cataluña, www.llibreblancmediacio.com.

LAUROBA, E. y ORTUÑN, P., Mediación es Justicia. El impacto de la Ley 5/2012, de Mediación civil y mercantil, Huygens, Barcelona, 2014.

LAUROBA, E., BARRAL, I.y VIOLA, I. (dirs); Tarabal, J. y Esteve, G. (coords.) Materiales jurídicos del Libro blanco de la mediación en Cataluña, Generalitat de Catalunya, Departament de Justícia, Centre d'Estudis Jurídics i Formació Especialitzada, Barcelona, 2011.

MACHO GÓMEZ, C., "Origen y evolución de la mediación: el nacimiento del «movimiento ADR» en Estados Unidos y su expansión a Europa", Anuario de Derecho Civil, (vol. 67, núm. 3, 2014), pp. 931-996.

MARQUES CEBOLA, C., La mediación, Marcial Pons, Madrid, 2013.

MARTÍN CASALS, M., "Comentario a la Disposición Final Tercera", en Egea, J. y Ferrer, J. (dirs.) y Lamarca, A. y Ruisánchez, C. (coords.), Comentaris al Codi de Família, a la llei d'unions estables de parella i a la llei de situacions convivencials d'ajuda mútua, Tecnos, Madrid, 2000.

MARTÍN CASALS, M., "Divorce Mediation in Europe: An Introductory Outline", Journal electronical comparative law, (vol 9.2, julio 2005), http:// www.ejcl.org/92/art92-2.html

MARTÍN DIZ, F., "Alternativas extrajudiciales para la resolución de conflictos civiles y mercantiles: perspectivas comunitarias", La Ley, (núm. 3, 2006), pp. 1637-1654.

MARTÍN DIZ, F., La mediación: sistema complementario de Administración de Justicia, Consejo General del Poder Judicial, Madrid, 2010.

MARTÍN DIZ, F., "Mediación en derecho privado: nuevas perspectivas prácticas", Revista General del derecho procesal, (núm.33, 2014). 
MERINO ORTIZ, C. y LASHERAS HERRERO, P., "Comentario al artículo 9”, en Castillejo Manzanares, R. (dir.) y Alonso Salgado, C. y Rodríguez Alvarez, A. (coords.), Comentario a la Ley 5/2012, de Mediación en asuntos civiles y mercantiles, Tirant lo Blanch, Valencia, 2013.

MORALES FERNÁNDEZ, M ${ }^{a}$ G., "La mediación, contenido de la tutela efectiva”, en Lauroba, E. y Ortuño, P., Mediación es Justicia. El impacto de la Ley 5/2012, de Mediación civil y mercantil, Huygens, Barcelona, 2014, pp. 99-107.

ORTÍZ PRADILLO, J. C., "La mediación como método de solución de conflictos en el estado de las autonomías" en Iglesias Canle, I. C., Mediación, justicia y Unión Europea, Tirant lo Blanch, Valencia, 2014.

ORTUÑO, P., "Comentario al art. 233-6", en Egea Fernández, J. y Ferrer Riba, J. (dirs.) y Farnós i Amorós, E. (coord.), Comentari al llibre segon del Codi civil de Catalunya. Família i relacions convivencials d'ajuda mútua, Atelier, Barcelona, 2014.

ORTUÑO, P., "Libro verde sobre las modalidades alternativas de resolución de conflictos en el ámbito civil y mercantil de 19 de abril de 2002 de la Comisión de las Comunidades Europeas", Revista Iuris-La Ley, (núm. 77, nov. 2003), pp. 42-47.

ORTUÑO, P., "Apuntes críticos sobre la Ley 5/2012, de mediación civil y mercantil”, Anuario de Mediación y Solución de Conflictos, (núm. 1, 2013), pp. 45-69.

ORTUÑO, P., "Comentario al artículo 1. Concepto", en Castillejo Manzanares, R. (dir.) y Alonso Salgado, C. y Rodríguez Alvarez, A. (coords.), Comentario a la Ley 5/2012, de Mediación en asuntos civiles y mercantiles, Tirant lo Blanch, Valencia, 2013.

ORTUÑO, P., "El impulso a la mediación en la experiencia de los PNPM", en Lauroba, E. y Ortuño, P., Mediación es Justicia. El impacto de la Ley 5/2012, de Mediación civil y mercantil, Huygens, Barcelona, 2014.

ROBLES LATORRE, P., "Apuntes sobre la Directiva de Mediación en asuntos civiles y mercantiles", Revista de Derecho Privado, (noviembre-diciembre, 2008), pp. 97-111.

VALL, A., "Sistemas mixtos de gestión colaborativa de conflictos", en Lauroba, $\mathrm{M}^{\mathrm{a}}$ E., Barral, I. y Viola, I., Materiales jurídicos del Libro Blanco de la mediación en Cataluña, Generalitat de Catalunya, Barcelona, 2011.

VIOLA, I., "La confidencialidad en el procedimiento de mediación", en Lauroba, $\mathrm{M}^{\mathrm{a}}$ E., Barral, I, y Viola, I., Materiales jurídicos del Libro Blanco de la mediación en Cataluña, Generalitat de Catalunya, 2011. 